\title{
Research Significance of Architectural Color in Modern Chinese Universities
}

\author{
Dapeng Zhou ${ }^{1, *}$ \\ ${ }^{1}$ School of Art \& Design, Guangdong Industry Polytechnic, Guangzhou, Guangdong, China \\ "Corresponding author. Email: zhoudapeng@126.com

\begin{abstract}
With the intensification of economic globalization, the regional characteristics of architecture are gradually disappearing, and architectural color plays a great role as an important means to reshape and protect regional characteristics and culture. The regional differences of the architectural colors of modern colleges and universities determine that the regional architectural colors can be regarded as the characteristics of local culture, which reveals the regional manifestations of the architectural colors. It is of practical significance to study the treatment methods of the architectural colors.
\end{abstract}

Keywords: university architecture, architectural color, value

\section{INTRODUCTION}

The city composed of buildings is a highly concentrated social material system of population, economy, politics and culture formed in history. "It is a residential area with a certain population size and mainly non-agricultural population, which is a special form of settlement". It is also the embodiment of the development of human civilization. "The architectural landscape marks the existence of human civilization and is the visual image of various physical environments in the city (including the natural environment and artificial environment in the city) obtained through human perception." The man-made landscape features made up of buildings are the most direct reflection of a region's economic development, residents' quality of life and regional cultural traditions.

\section{THE ABSENCE OF REGIONAL COLOR CULTURE AGAINST THE BACKGROUND OF GLOBALIZATION}

In terms of visual perception, architecture can be understood as a space composed of "form" and "color". Color has a strong role in spatial identification, spatial modeling and spatial regulation, and can convey emotions that cannot be expressed by form and morphological elements, thus playing a unique role in shaping architectural images. Architecture itself is an expression of color, and people live in some kind of color relationship in the urban space constructed by architecture. Harmonious and good architectural color reflects the vitality of architecture, indicates the expression of the cultural composition of the architectural environment, and more importantly, implies the value and cultural fashion of people living in this particular region. Color is very important in urban space, which is the source of the sense of belonging to one's own living environment and the spirit of place.

At present, the architectural color in many Chinese cities lacks order and is extremely chaotic: rigid architectural colors, disordered colors in outdoor advertisements, lack of basic connections and coordination between buildings and between buildings and between buildings and the environment, and even "color pollution". Color pollution refers to the phenomenon that improper use of color in urban environment has a negative impact on people's physical and psychological feelings and damages the urban landscape.

The use of architectural color in the traditional era is restricted by specific materials, technology, society, economy and other conditions, forming a regional color habit. Architectural color can naturally form a style and appearance. Thanks to the development of technology, the constant emergence of new materials and the convenient exchange of information, people can easily obtain the building materials of colors needed by modern architecture and pursue their favorite style. This provides more conditions for the richness and diversity of architectural colors, but it also provides conditions for the abuse of colors, thus the architectural colors become chaotic. Such chaotic state is the lack of architectural color integrity, resulting from the lack of scientific and reasonable color planning and strong management measures.

Due to the impact of globalization and popularity factors, the absence of regional and national character and the rupture of context in architectural color presents a variety of missing trends. The imbalance of cultural 
exchange leads to the lack and gradual disappearance of regional characteristics in some regions. Different regions show the tendency of convergence; The single region also fails to reflect the differences in color. This trend leads to the loss of architectural diversity and character. Architectural color is actually the external embodiment of a region's internal cultural characteristics, is an important content of cultural inheritance and development, should have a unique local and national character. Architectural color plays an irreplaceable role. The expression of regional culture through color is an important aspect of obtaining regional characteristics and individual development under the general trend of globalization and rapid urbanization.

\section{ARCHITECTURAL COLOR RESEARCH AND PRACTICE}

In the process of planning, design, development, construction and management decision-making, there are still some misunderstandings about the current architectural color in China. These misunderstandings come from government management departments, planning and design agencies and developers, which directly or indirectly lead to the formation of color problems.

The first is to seek uniqueness deliberately. Driven by interests, the concept of innovation is gradually alienated, which makes the whole architectural activity the experimental site of various styles. The lack of holistic consciousness and deliberate pursuit of novelty have a huge impact on the overall image of the city, including the harmony and order of architectural colors, resulting in the loss of the overall harmony of architectural colors.

Secondly, a large number of "constructive destruction" has led to a sharp decline in the number of historical and cultural heritage and historical features. A basic principle of protecting historical heritage has become the consensus of the whole society. Therefore, the relationship between old and new buildings, tradition, locality and present should be dealt with according to the principle of "coordination". However, the concept of coordination in practice is more simplified as "similar" and "identical". Such inferior coordination weakens the appeal of the original building and causes great damage to the style and landscape.

Faced with the above problems, relevant departments and people in China and abroad have conducted various researches and analyses, and put forward some influential theories, among which the theory of "color geography" founded by Jean-Philippe Lenclos is the most influential. Jean Philippe Loncolo is a famous French colorist, who has been devoted to the three-dimensional color design and application for a long time. By comparing the colors of different regions in different parts of the world, he found that the relationship between beauty and cultural difference is related to geographical factors. Thus, he focused his chromatics on geography, the foundation underpinning cultural phenomena. Based on geography, looking at the peculiar color phenomena in different geographical locations, he found that different geographical environments directly affected the formation and development of human beings, races, customs, cultures and other aspects, which led to different color expressions. Therefore, he put forward the concept of "color geography".

\section{RESEARCH VALUE OF ARCHITECTURAL COLOR IN MODERN CHINESE UNIVERSITIES}

The period from 1840 to 1949 was the period of modern Chinese architecture. The first generation of Chinese architects initiated the discussion and practice of "Chinese inherent form" architecture, aiming at inheriting the fine tradition of Chinese traditional architectural art and creating Chinese national form architectural works on the basis of accepting western modern architectural techniques, functions, systems and design methods. However, tracing back to the source, western architects at least began to explore the Sinicization of missionary university school buildings at the end of the 19th century, which was the earliest attempt by architects to explore the national form of Chinese architecture. Going back further, in the middle of the 19th century, the folk houses in Shanghai had produced a mix of Chinese and Western houses in Shikumen Lane, which was an early unconscious exploration of the national form of Chinese architecture by non-architects. Chronologically, the exploration of the unconscious from the folk, the exploration of the Western architects in the field of missionary university buildings, and the comprehensive exploration of the first generation of Chinese architects formed a trilogy of the exploration of the national forms of Chinese architecture in modern times (1840-1949).

Modern education department is one of the most modernized departments in China, and also one of the sources of Chinese new culture. As a new type of architecture in modern China, the educational architecture of modern universities has become an important part of modern architecture and attracted more attention. People have gradually realized the historical and cultural value of modern buildings, an important symbol of which is that they have been listed in the list of national key cultural relics protection units. The site of Nankai University was listed in the fourth batch of national key cultural relics protection units. Four modern university buildings are listed in the fifth batch of national key cultural relics protection units. 
They are the early buildings of Tsinghua University, The Yanyuan building of Weiming Lake of Peking University, the early buildings of Wuhan University and the site of Northeast University. These colleges and universities are the earliest "new-style" colleges and universities in the modern history of China. Most of these buildings were built at the beginning of the 20th century and have high historical, artistic and scientific values, which can be regarded as the models of modern Chinese architecture. In the past, most of the studies on these buildings started from the overall campus planning and architectural form, but there were few studies on architectural color and color region. (See "Fig. 1" and "Fig. 2")

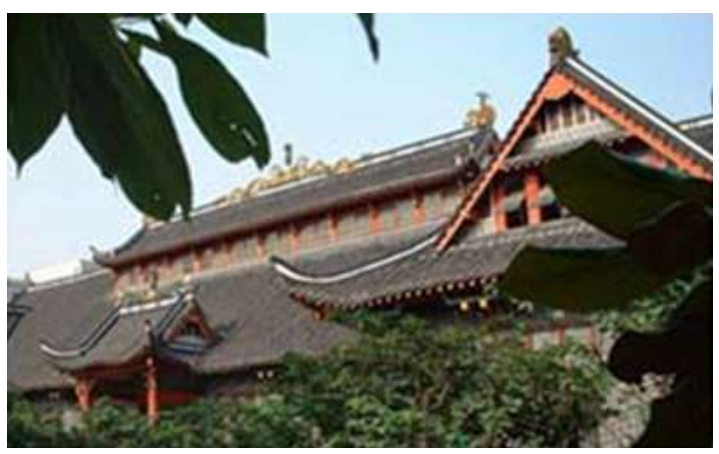

Fig. 1. West China Center of Medical Sciences, Sichuan University (picture source: Sichuan University website).

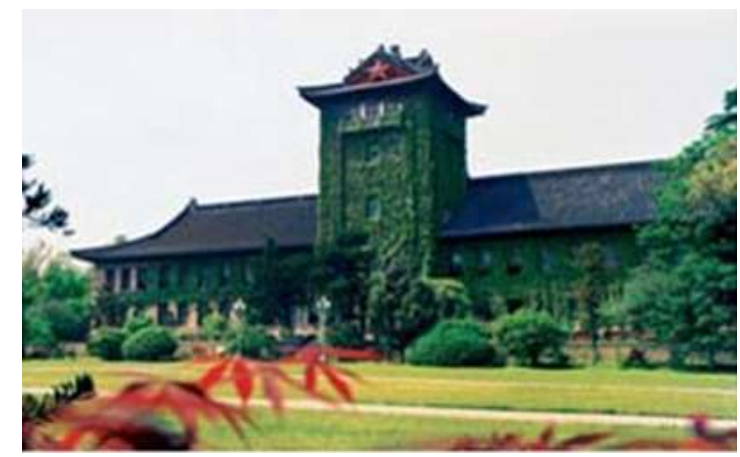

Fig. 2. Nanjing Normal University (picture source: Nanjing Normal University website).

\section{THE SIGNIFICANCE OF ARCHITECTURAL COLOR RESEARCH IN MODERN CHINESE UNIVERSITIES}

Different geography inevitably leads to specific regional environment, and different environment constitutes different climatic conditions, thus affecting the lifestyle and customs of different people living here, and even producing different cultures, forming different regional environmental landscapes. This paper discusses the relationship between the formation and development of regional architectural color culture and regional characteristic elements, and analyzes the relationship between the architectural color and specific regional elements one by one. Taking Chinese modern university architecture as the entry point, the relationship between the formation and development of regional architectural color culture and regional characteristic elements is discussed by analyzing the relationship between the color of Chinese modern university architecture and specific regional elements one by one. As an important cultural carrier, university architecture plays an indispensable role in regional difference. In various regions, the function of architectural color is very important. Color, like other cultural elements, should be subordinate to and reflect regional culture.

Up to now, China's architecture and urban color planning has not formed a complete theoretical system and scientific and effective methods, there are many difficulties in theory and practice: First of all, the positioning of architectural color. Positioning is the primary and basic problem to realize the rational harmony and characteristics of city colors. The second is to realize the scientific, reasonable and effective control of color in architectural color planning. The reality is that the methods and means of control are either not practical and ineffective, or attempt and accomplish nothing. Without a concrete and feasible planning control method, the implementation of management will become empty talk. Therefore, practical, reasonable, flexible, scientific and effective control method is the key to the realization of architectural and urban color planning.

\section{CONCLUSION}

Color should be an excellent material and discourse for the expression of architectural culture characteristics. As a visible phenomenon on the surface of culture, color actually reflects the cultural connotation and essence of a region from a specific angle. The complete separation and abandonment of the traditional regional architectural color is equal to the abandonment and separation of traditional culture. The intensification of economic globalization makes the regional features of architecture disappear gradually. Visionary people, local governments and professionals should begin with architectural color and try to reshape and protect regional characteristics and culture.

\section{References}

[1] Zhang Siqi, Zhang Baomin, Huang Shuai, Shu Chang, Ji Mingyan, Zhou Jingyi. A study on the campus color planning in colleges and universities [J]. Housing, 2019(32): 4. (in Chinese)

[2] Li Ling. The Application of Environmental Colorology in College Campus Architecture and Landscape Design [J]. Art Science and Technology, 2014, 27(08): 17-18+20. (in Chinese) 
[3] Feng Xingyu. Analysis of the Color Modeling of College Campus Architecture [J]. North West Fine Arts, 2014 (02): 134135. (in Chinese)

[4] Zhou Dapeng. Regional Study on Architectural Colors of Modern Chinese Colleges [D]. Jiangnan University, 2008. (in Chinese)

[5] Feng Xingyu, On the Color Modeling of College Campus Architecture [J]. North West Fine Arts, 2014 (02): 134-135. (in Chinese)

[6] Sun Qin, The Color Design for Architectures of Universities with the Concept of Geographical Color [J]. Shanxi Architecture, 2009, 35(01): 57-59. (in Chinese) 